\title{
Cardiac magnetic resonance perfusion imaging and the effects of single intravenous cannulation with the Octopus bionector
}

\author{
Heiko E Kindler, Eliana Reyes, Arun J Baksi, Arun Natarajan, Harith Alam, John-Paul Carpenter, Raad Mohiaddin, \\ Peter D Gatehouse, Dudley Pennell
}

From 16th Annual SCMR Scientific Sessions

San Francisco, CA, USA. 31 January - 3 February 2013

\section{Background}

CMR perfusion (CMRP) imaging using adenosine traditionally requires bilateral arm cannulation. Patients with multiple comorbidities often have difficult venous access and dual cannulation often proves impossible. We used a standard two-way adapter (Octopus Vygon with no-reflow valve) to administer adenosine at a standard rate of 140 $\mathrm{mcg} / \mathrm{kg} /$ minute over 3 minutes for maximum coronary vasodilatation following a bolus injection of gadolinium. High flow bolus injection may cause sinus arrest caused by a flush of residual adenosine in the same arm vein. We acquired 50 sequential $\mathrm{R}$-wave triggered image frames to assess first pass myocardial perfusion and assessed the effect of significant sinus pauses on image acquisition.

\section{Methods}

First pass perfusion was performed on a Siemens Avanto1.5T MR scanner (Siemens Medical Solutions, USA) with a standardised acquisition protocol using intra-venous adenosine $140 \mu \mathrm{g} / \mathrm{kg} / \mathrm{min}$ for 3 minutes. Three sequential short axis slices of $8 \mathrm{~mm}$ thickness were acquired per cardiac cycle using a hybrid EPI sequence (TR $175 \mathrm{~ms}$, TE $1.03 \mathrm{~ms}$, flip angle 25 degrees and voxel size $2.8 \mathrm{x}$ $2.8 \times \mathrm{mm}^{2}$ ) after administration of a $0.1 \mathrm{mmol} / \mathrm{Kg}$ bolus of intravenous Gadolinium (Gadovist). Fifty sequential $\mathrm{R}$-wave triggered frames were acquired to assess first pass perfusion. We assessed the effect of significant sinus pauses on patient safety and quality of image acquisition.

\section{Results}

One hundred and seven CMRP studies using the Octopus two-adapter were compared with 107 standard method

CMR Unit, Royal Brompton Hospital, London, UK, London, UK dual vein cannulation for CMR first pass perfusion between May 2012 and August 2012. Twenty seven of 105 patients (25.7\% vs $0 \%$ in the control group) developed significant episodes of bradycardia. Mean heart rate 69.1 (+/-28.1) Range: 139-18 min-1). Image sequences during first pass perfusion were adversely affected due to gaps in $\mathrm{R}$-wave triggered image frame acquisition during, or just before gadolinium arrival because of the effects of adenosine (Figures 1 and 2).

\section{Conclusions}

Crucial image frames are not acquired at the most important time points during first pass perfusion in $26 \%$ of patients with the Octopus Bionector. The introduction of a two-way intravenous adapter resulted in an

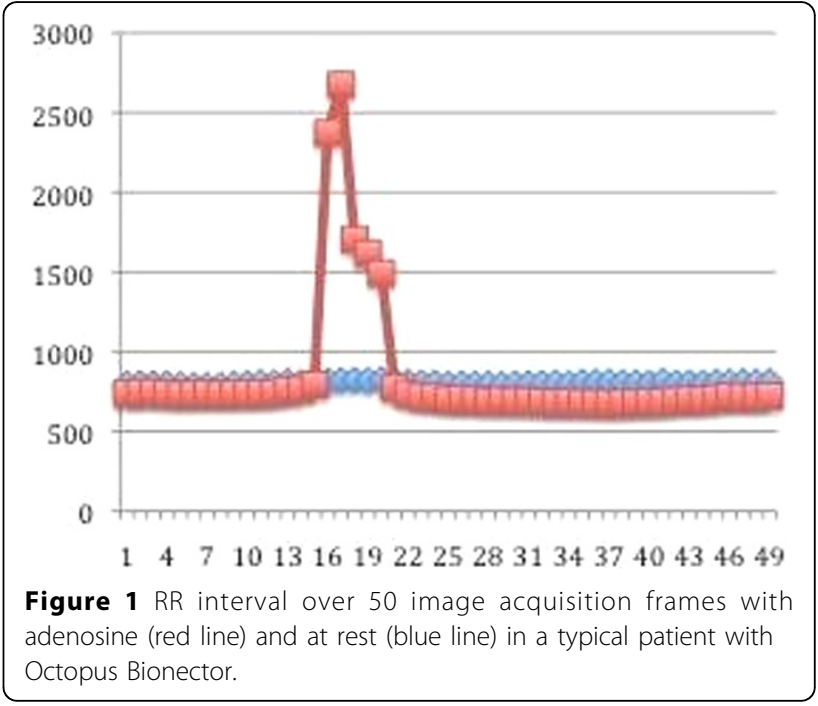

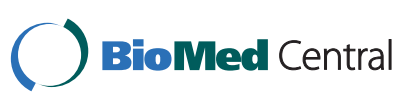

(c) 2013 Kindler et al; licensee BioMed Central Ltd. This is an Open Access article distributed under the terms of the Creative Commons Attribution License (http://creativecommons.org/licenses/by/2.0), which permits unrestricted use, distribution, and reproduction in any medium, provided the original work is properly cited. 


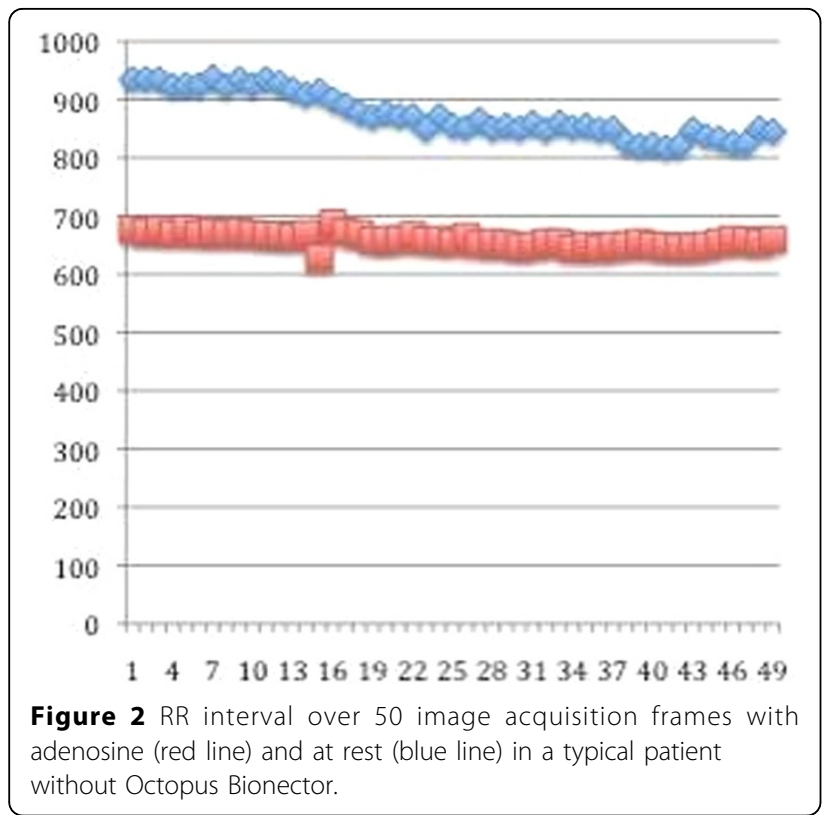

unacceptably high number of patients having sinus pauses/sinus arrest over several seconds, And as image quality is heavily dependent on $\mathrm{R}$ wave intervals being regular, this adversely affected image quality. This could have led to underdiagnosis of perfusion defects in the affected patients.

\section{Funding}

N/A.

Published: 30 January 2013

doi:10.1186/1532-429X-15-S1-053

Cite this article as: Kindler et al:: Cardiac magnetic resonance perfusion imaging and the effects of single intravenous cannulation with the

Octopus bionector. Journal of Cardiovascular Magnetic Resonance 201315 (Suppl 1):O53.
Submit your next manuscript to BioMed Central and take full advantage of:

- Convenient online submission

- Thorough peer review

- No space constraints or color figure charges

- Immediate publication on acceptance

- Inclusion in PubMed, CAS, Scopus and Google Scholar

- Research which is freely available for redistribution

Submit your manuscript at www.biomedcentral.com/submit 